\title{
Adsorption of Methylene Blue Dye onto Bush Cane Bark Powder
}

\author{
Conrad K. Enenebeaku ${ }^{1, a^{*}}$, Nnaemeka J. Okorocha ${ }^{2, b}$, \\ Uchechi E. Enenebeaku ${ }^{3, c}$, Benedict I. Onyeachu ${ }^{4, d}$ \\ ${ }^{1,2,4}$ Department of Chemistry, Federal University of Technology, Owerri, PMB 1526, Nigeria \\ ${ }^{3}$ Department of Biotechnology, Federal University of Technology, Owerri, PMB 1526, Nigeria \\ aenecon92002@yahoo.com, bemybeck@yahoo.com, ${ }^{\mathrm{C}}$ ucheodionye@yahoo.com, \\ dbenedictonyeachu@gmail.com
}

Keywords: Methylene Blue; Bush Cane bark powder; Adsorption; Freundlich isotherm.

\begin{abstract}
The adsorption of methylene blue (MB) dye on bush cane bark powder has been studied by analyzing the effect of contact time, initial dye concentration, adsorbent dose, $\mathrm{pH}$, and temperature on the amount of the MB dye adsorbed per unit mass of the bush cane bark powder adsorbent. An optimum adsorption could be achieved during 80 min contact time but, thereafter, decreased with contact time beyond $80 \mathrm{~min}$. The adsorption of the methylene blue dye increased with increasing the initial dye concentration, temperature and $\mathrm{pH}$. However, the amount of methylene blue adsorbed decreased with increasing the dosage of the adsorbent; a phenomenon attributed to a plausible agglomeration of the adsorbent and blocking of the preferred adsorption sites with increasing adsorbent dosage. The adsorption mechanism of the dye obeyed the Freundlich isotherm. Kinetic studies showed that the methylene blue adsorption onto bush cane bark powder adsorbent followed a second order reaction kinetics. The adsorbent was characterized by Fourier transform infra-red spectrophotometer and scanning electron microscope analysis.
\end{abstract}

\section{Introduction}

Dyes are highly employed for coloration in many textile, paper and food processing industries. The discharge of these dyes in effluents emanating from such industries is a major cause of serious environmental pollution [1,2], since, when discharged, the dyes can seriously hinder the penetration of light and disturb the biological processes occurring in many water bodies. More so, the natural degradation of these dye compounds, when released into the environment, usually yields highly toxic and carcinogenic products [3-5]. Compared with well-known techniques like filtration, precipitation, coagulation and ozone treatment for the removal of dyes from effluents, the adsorption technique provides greater merits of simplicity and very low cost involvement.

Activated carbon is, by far, one of the oldest and most employed adsorbents for the removal of many dyes from solutions because of its high surface area and porosity [6]. However, the continuous use of commercially available activated carbon is limited by its high cost. This has led researchers into studying the efficacy of relatively cheaper and readily available unconventional adsorbents derived from plant materials to function as effective adsorbents for dyes [7-11].

Bush cane plant, Costus afer, which belongs to the family Zingiberaceae is a monocot and a tall perennial semi-woody herb with leaf cane about $3 \mathrm{~cm}$ high and bearing a terminal inflorescence of white and yellow flowers. It is among 150 species of stout, unbranched and creeping rhizomatous herbs of genus Costus. It is mostly found in west and tropical Africa [9-11]. The extracts from the plant have been shown to exhibit pharmacological properties against malaria, constipation, edema and fever $[12,13]$.

The objectives of this study is to investigate the ability of bush cane bark powder (BCBP) to remove the cationic dye, methylene blue (MB) from the simulated solution. The effects of contact time, initial dye concentration, adsorbent dose, temperature and $\mathrm{pH}$ on the amount of $\mathrm{MB}$ adsorption on BCBP were investigated. The adsorption kinetics, isotherms and thermodynamics of the adsorption reaction were also analyzed. 


\section{Literature Review}

Jack fruit peel has been investigated as adsorbents for removal of Methylene blue by Hameed [14] using batch adsorption method. The effect of different system variables like adsorbent dose, initial dye concentration, contact time and $\mathrm{pH}$ were evaluated. He found that as the amount of adsorbent increased, the percentage of dye removal increased accordingly. Also low concentrations of Methylene blue favored high adsorption percentages and the optimum $\mathrm{pH}$ value for dye adsorption was found to be 4.0. The equilibrium biosorption data were analyzed using four different types of linearized Langmuir isotherm, the Freundlich isotherm and the Temkin isotherm. Best fits were obtained with the type 2 Langmuir model. The sorption capacity of Methylene blue on jackfruit peel was found to be $285.713 \mathrm{mg} / \mathrm{g}$.

Garlic peel was investigated by Hameed and Ahmad [15] for the removal of Methylene blue from aqueous solution. Equilibrium isotherms were determined and analyzed using the Langmuir, Freundlich and Temkin isotherms. The maximum monolayer adsorption capacities were found to be $82.64,123.45$ and $142.86 \mathrm{mg} / \mathrm{g}$ at 303,313 and $323 \mathrm{~K}$ respectively. Batch studies were carried out to explore the potential use of garlic peel as low-cost adsorbent for Methylene blue removal from aqueous solution. The kinetic data were analyzed using pseudo-first-order and pseudo-second-order models. The investigators observed that the adsorption capacity was higher due to the presence of polar functional group.

Pine apple stem was studied by Hameed et al. [16] for the adsorption of Methylene blue (basic dye) from aqueous solution. The batch adsorption process was studied at different concentration of dyes, contact time, and $\mathrm{pH}$ and was found to obey the Langmuir isotherm. The investigators suggested that the acidic $\mathrm{pH}$ is favorable for the adsorption. The maximum adsorption capacity on pine apple stem for the removal of Methylene blue was found to be $119.05 \mathrm{mg} / \mathrm{g}$.

Broad bean peel an agricultural waste chopped, sieved, washed and oven dried at $60^{\circ} \mathrm{C}$ for 48 hours was used by Hameed and El-Khaiary [17] for removal of cationic dye (Methylene blue) and adsorption capacity of $192.7 \mathrm{mg} / \mathrm{g}$ was obtained. It was noted that adsorption of dye decreases with an increase in the initial Methylene blue concentration. The adsorption of dyes was reported to follow Langmuir adsorption model and pseudo-first-order kinetic model

Hameed [18] studied papaya seeds a novel non-conventional low-cost adsorbent for the removal of (cationic dye) Methylene blue. The effect of dye adsorption increased with increase in adsorbent dosage and $\mathrm{pH}$. In terms of the initial rate of adsorption, the uptake of the cationic dye on to papaya seeds was found to occur more rapidly. The intraparticle diffusion indicated that more than one process affected the adsorption. The removal of Methylene blue by papaya seeds suggested that the sorption interaction obeyed the pseudo-second-order kinetics. The equilibrium data for Methylene blue on papaya seeds were modeled with the Langmuir, Freundlich, and Temkin models. The data fitted well with the Langmuir model with a maximum monolayer capacity of $555.557 \mathrm{mg} / \mathrm{g}$.

Ponnusami et al. [19] studied Gulmohar (Delonix regia) as adsorbent for the removal of Methylene blue from aqueous solution. The materials were studied without chemical treatment. The investigators found the adsorption was favorable at higher $\mathrm{pH}$ and lower temperature. The equilibrium data were well fitted by the Langmuir isotherm an appreciable Langmuir capacity of $0.3 \mathrm{mg} / \mathrm{g}$ was found out.

\section{Experimental}

\section{Preparation of BCBP adsorbent}

The bush cane plants (Costus afer) were obtained from Federal University of Technology Owerri farm and its environs and identified at the Department of Crop Science at the Federal University of Technology Owerri, Nigeria. The collected peels were severally washed with tap water and double distilled water thereafter, stored at $50{ }^{\circ} \mathrm{C}$ until moisture content was stably insignificant. The dried bush cane bark were then crushed, sieved to pass through $150 \mu \mathrm{m}$ mesh 
size, collected into air-tight containers and kept in air-tight desiccators to be used as adsorbent without further preparation and labeled BCBP.

\section{Preparation of methylene blue dye solution}

Stock solution of methylene blue dye solution was prepared by dissolving $1 \mathrm{~g}$ of commercially available methylene blue (Fluka grade) in $1 \mathrm{~L}$ of distilled water to obtain a stock concentration of $1000 \mathrm{mg} / \mathrm{L}$. Experimental dye solutions of desired concentrations were prepared by appropriate dilution of stock solution.

\section{Adsorbent characterization}

Fourier transform infra-red (FTIR) spectrophotometer was used to identify the different functional groups available on the adsorbent sites. The FTIR of the adsorbent was taken before and after adsorption of methyl red using FTIR spectrophotometer (Shimadzu-8400S). The adsorbent was encapsulated with $\mathrm{KBr}$ spectroscopy grade and by introducing the mix in a piston's cell of a hydraulic pump with compression pressure $15 \mathrm{KPa} / \mathrm{cm}^{2}$, the solid transluscent disk was obtained. The FTIR spectrum was then recorded within the wave number range $4000-500 \mathrm{~cm}^{-1}$. In addition, surface morphology and texture of the adsorbent was analyzed using scanning electron microscope (SEM) (Model-PHENOM ProX). Prior to scanning, some quantity of the adsorbent was placed on a double adhesive sticker placed in a sputter machine for $5 \mathrm{sec}$; this gave the adsorbent a conductive property. Sample (adsorbent) stud was fixed on a charge reduction sample holder, and then was charged in the SEM machine.

\section{Batch Adsorption Experiments}

\section{Effect of Contact Time}

The effect of contact time on the adsorption of MB dyes onto bush cane back powder was performed as follows: $1 \mathrm{~g}$ of the adsorbent (BCBP) was weighed into seven different conical flasks. Concentration of $50 \mathrm{mg} / \mathrm{L}$ of the dye was prepared differently from the stock solution by dilution. $100 \mathrm{ml}$ of the $50 \mathrm{mg} / \mathrm{L} \mathrm{MB}$ dye solution was measured into the seven conical flasks. The flasks were labeled for time intervals of 10,20,40,60, 80, 100 and 120 minutes. The flasks were tightly covered and agitated on a rotary shaker $(100 \mathrm{rpm})$ at the appropriate time intervals and at room temperature $\left(27^{\circ} \mathrm{C}\right)$. At the end of each time interval, the flasks were withdrawn and filtered using Whatman No.1 filter paper. The concentration in the supernatant solution was analyzed using UVvisible Spectrophotometer.

\section{Effect of Adsorbent Dose}

The Batch adsorption experiment on the effect of adsorbent dosage on the adsorption of Methylene blue dye onto bush cane bark powder was performed by weighing $0.5,1,2,3$ and $4 \mathrm{~g}$ of the adsorbent (BCBP) into five different conical flask respectively. $100 \mathrm{ml}$ of each dye solution of concentration $50 \mathrm{mg} / \mathrm{L}$ was measured into the five conical flasks. The flasks were then labeled for different dosage of time intervals of $0.5,1,2,3$ and $4 \mathrm{~g}$. The flasks were tightly covered and agitated on a rotary shaker (100rpm) at contact time of optimum adsorption and at room temperature $\left(27{ }^{0} \mathrm{C}\right)$. Afterwhich the flasks were withdrawn and filtered using Whatman No.1 filter paper. The concentration in the supernatant solution was analyzed using UV-visible Spectrophotometer.

\section{Effect of Initial Concentration}

The Batch adsorption experiment on the effect of initial concentration on the adsorption of Methyl red dyes onto almond seed shell powder was carried as follows: Several standard Methyl red dye solutions of $25,50,75,100$ and $125 \mathrm{mg} / \mathrm{L}$ were prepared from their respective stock solution. The flasks were then labeled for the different dye concentration of $25,5075,100$ and $125 \mathrm{mg} / \mathrm{L} .100 \mathrm{ml}$ of each of the solution was added to accurately weighed $1 \mathrm{~g}$ of the adsorbent into the five different conical flask and agitated at contact time of optimum adsorption and at room temperature $\left(27{ }^{\circ} \mathrm{C}\right)$. At the end of the time intervals, the flasks were withdrawn and filtered using 
Whatman No.1 filter paper. The concentration in the supernatant solution was analyzed using UVvisible Spectrophotometer.

\section{Effect of pH}

The Batch adsorption experiment on the effect of $\mathrm{pH}$ on the adsorption of methyl red dyes onto almond seed shell powder was performed as follows: Several $\mathrm{pH}$ of the MB dye solutions of 2, $4,6,8$, and 10 were prepared using $0.1 \mathrm{M}$ of $\mathrm{HCl}$ or $\mathrm{NaOH}$ and measuring with a DEEP VERSION model (EI) $\mathrm{pH}$ meter. The flasks were then labeled for the different initial $\mathrm{pH}$ of 2, 4, 6, 8, and 10 . $100 \mathrm{ml}$ of each of the solution was added to accurately weighed $1 \mathrm{~g}$ of the adsorbent into the five different conical flasks and agitated at contact time of optimum adsorption and at room temperature $\left(27^{\circ} \mathrm{C}\right)$. At the end of the time intervals, the flasks were withdrawn and filtered using Whatman No.1 filter paper. The concentration in the supernatant solution was analyzed using UV-visible Spectrophotometer.

\section{Effect of Temperature}

The Batch adsorption experiment on the effect of temperature on the adsorption of methyl red dyes onto almond seed shell was carried out as follows: $1 \mathrm{~g}$ of the adsorbent was weighed into five conical flask and $100 \mathrm{ml}$ of the dye solution of concentration $50 \mathrm{mg} / \mathrm{L}$ was measured into the five conical flasks. The flasks were labeled for temperature of $30,40,50,60$ and $70{ }^{\circ} \mathrm{C}$. The flasks were tightly covered and heated at the appropriate temperature using thermostatic water bath at contact time of optimum adsorption. At the end of the timing schedule, each of the flasks was brought out and agitated for about five minutes. Then the solutions in the flasks were filtered using Whatman No. 1 filter paper. The final concentrations in the supernatant solution were determined using UVvisible spectrophotometer.

The amount of the MB dye adsorbed per unit mass of the BCBP adsorbent, $\mathrm{q}_{\mathrm{e}}$, was calculated for each experimental variable according the equation (1) below; where $C_{o}$ and $C_{e}(\mathrm{mg} / \mathrm{L})$ are, respectively, the initial and equilibrium dye concentration in the liquid phase, $\mathrm{V}$ (L) is the initial volume of the dye solution and $\mathrm{W}(\mathrm{g})$ is the mass of the adsorbent

$$
q e=\frac{(C o-C e) V}{W} \text {. }
$$

\section{Adsorption mechanism and kinetics}

The mechanism of the adsorption was tested by fitting the experimental values of $C_{e}$ (concentration of dye at equilibrium) and $\mathrm{q}_{\mathrm{e}}$ (amount of dye adsorbed per unit mass of adsorbent at equilibrium) into the Langmuir and Freundlich isotherms models for the different initial dye concentrations after $80 \mathrm{~min}$. agitation at $100 \mathrm{rpm}$ in the presence of $1 \mathrm{~g}$ of $\mathrm{BCBP}$ at $27{ }^{\circ} \mathrm{C}$. The kinetics of the adsorption process was fitted to the first and second order of reaction based on the experimental values of $\mathrm{q}_{\mathrm{e}}$ (amount of dye adsorbed per unit mass of adsorbent at equilibrium) and $\mathrm{q}_{\mathrm{t}}$ (amount of dye adsorbed at a given time) for the varying contact time $20 \mathrm{~min}$. to $120 \mathrm{~min}$.

\section{Results and Discussion}

\section{Effect of contact time on MB adsorption}

In the presence of $1 \mathrm{~g}$ of BCBP adsorbent, $100 \mathrm{~mL}$ of $50 \mathrm{mg} / \mathrm{L} \mathrm{MB}$ solution, at $27{ }^{\circ} \mathrm{C}$ and under $100 \mathrm{rpm}$ agitation, the plot for the variation of the amount of MB dye adsorbed per unit mass of the adsorbent, $\mathrm{q}_{\mathrm{e}}$, during different contact times is provided in Fig. 1. An increase in the $\mathrm{q}_{\mathrm{e}}$ value occurred as contact time increased from $10 \mathrm{~min}$. reaching an optimum value of $4.777 \mathrm{mg} / \mathrm{g}$ during 80 min. of contact. Nevertheless, the $\mathrm{q}_{\mathrm{e}}$ values sharply dropped slightly and remained unchanged at $4.754 \mathrm{mg} / \mathrm{g}$ beyond $80 \mathrm{~min}$. contact time. The result shows that increasing contact time favors the prolonged interaction between the MB molecules and the BCBP surface and subsequent permeation into the adsorbent pores until saturation is attained during $80 \mathrm{~min}$. Nevertheless, the sharp loss of adsorbed MB molecules, and subsequent re-establishment of equilibrium $\mathrm{q}_{\mathrm{e}}$ value, with contact time 
beyond $80 \mathrm{~min}$. indicates that the dislodged MB molecules were weakly held during saturation. This is feasible for the formation a secondary adsorption layer (held with weak bond) on a primarily adsorbed MB layer (having stronger attachment with the BCBP substrate). Assuming the MB molecules adsorb on heterogeneous sites on the BCBP surface, such could also provide an un-even spread of energy between the primary and secondary adsorption layers and, hence, facilitate the dislodging of $\mathrm{MB}$ dye beyond the $80 \mathrm{~min}$. optimum contact time.

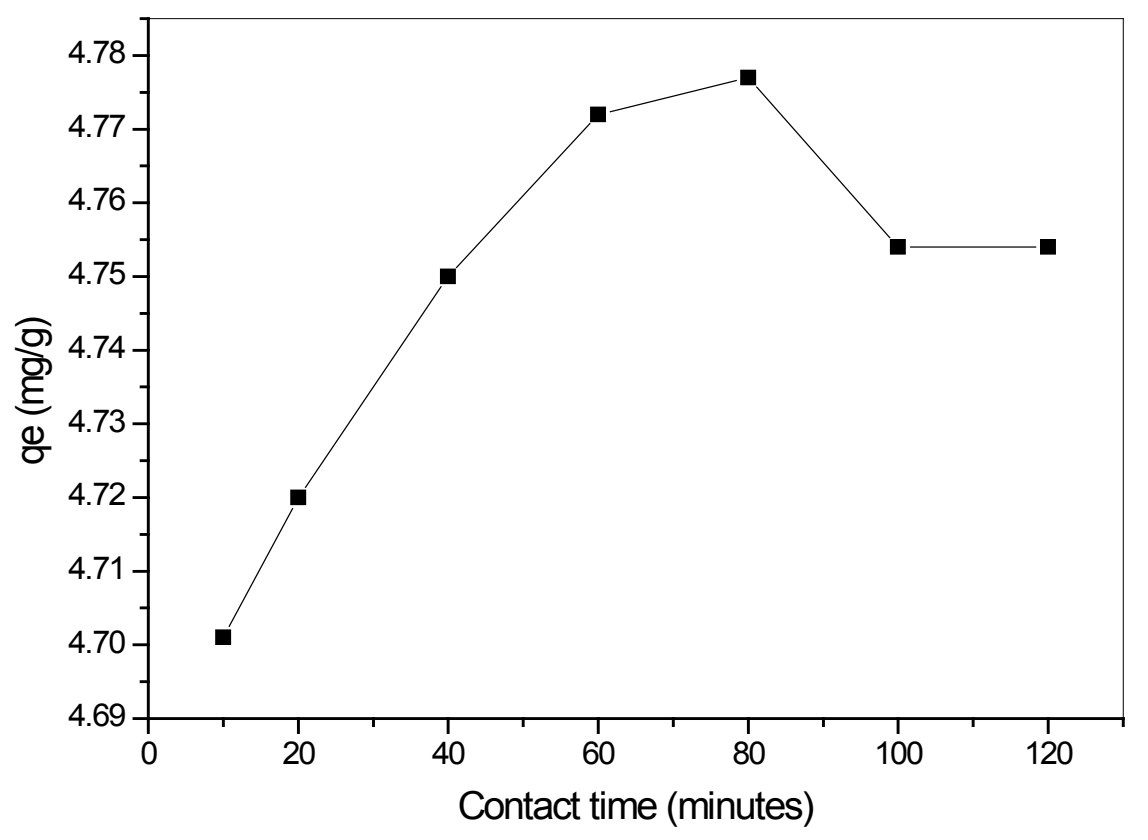

Figure 1. Effect of contact time on the adsorption of MB.

\section{Effect of initial dye concentration on MB adsorption}

The Fig. 2 shows the variation of amount of $M B$ adsorbed, $\mathrm{q}_{\mathrm{e}}$, for different initial dye concentration in the presence of $1 \mathrm{~g} \mathrm{BCBP}$ adsorbent and after $80 \mathrm{~min}$ contact time at $27{ }^{\circ} \mathrm{C}$. The result clearly shows that the $\mathrm{q}_{\mathrm{e}}$ value steadily increased from $2.301 \mathrm{mg} / \mathrm{g}$ in the presence of $25 \mathrm{mg} / \mathrm{L}$ of MB to a maximum of $11.987 \mathrm{mg} / \mathrm{g}$ in the presence of $125 \mathrm{mg} / \mathrm{L}$ of $\mathrm{MB}$. Such trend has also been reported for the adsorption of many dyes on several other adsorbents [20,21]. This is quite understandable, given that increasing the initial dye concentration for a fixed adsorbent dose promotes a concentration gradient that continuously overcomes the resistance to the mass transfer of the dye from solution to the BCBP surface. Thus, the adsorption of MB and subsequent permeation into the pores of the adsorbent, are both facilitated with increasing dye concentration. Assuming the formation of weak bonds between primary and secondary adsorption layers or between $\mathrm{MB}$ and heterogeneous sites on BCBP, such effects could conveniently be overcome by increasing initial dye concentration. This is the reason that the $\mathrm{q}_{\mathrm{e}}$ values continued to increase as initial dye concentration increases. 


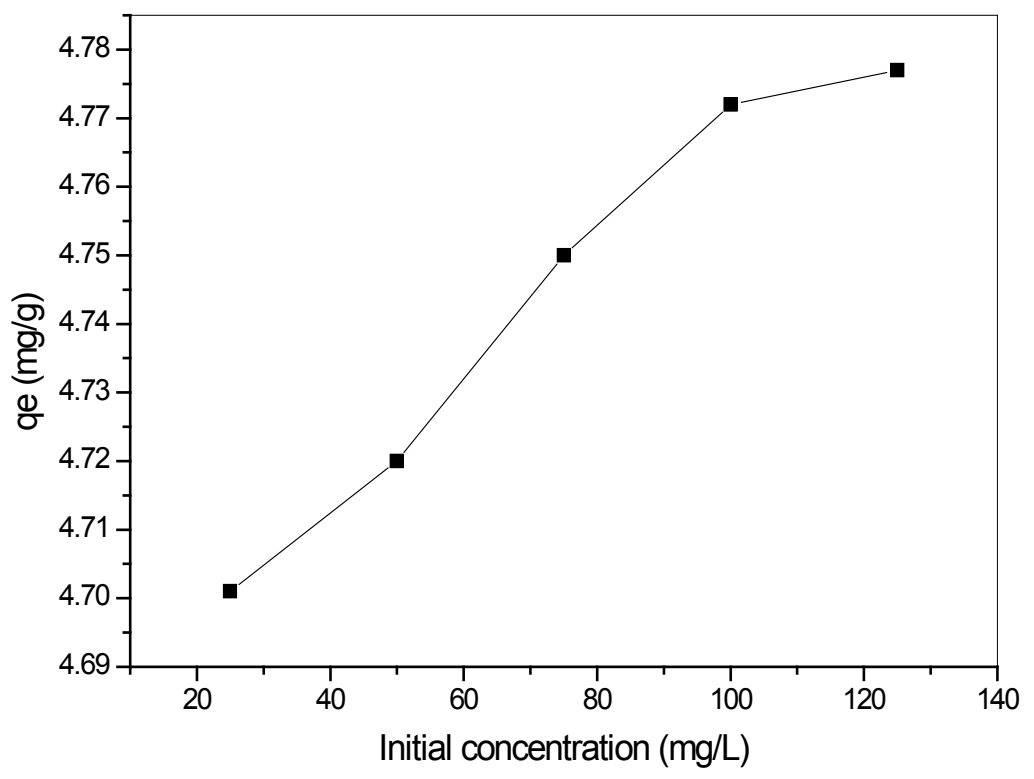

Figure 2. Effect of initial dye concentration on the adsorption of MB.

\section{Effect of adsorbent dosage on MB adsorption}

Fig. 3 shows the plot of the amount of MB dye adsorbed per unit mass of the BCBP adsorbent, $\mathrm{q}_{\mathrm{e}}$, in the presence of $100 \mathrm{~mL}$ of $50 \mathrm{mg} / \mathrm{L} \mathrm{MB}$ solution with adsorbent dosage varying from $0.5 \mathrm{~g}$ to $4.0 \mathrm{~g}$ and after $80 \mathrm{~min}$ agitation time. The result shows that the qe values actually decreased as the adsorbent dosage increased; exhibiting a maximum value $(9.313 \mathrm{mg} / \mathrm{g})$ in the presence of $0.5 \mathrm{~g}$ of the BCBP adsorbent and a minimum of $1.245 \mathrm{mg} / \mathrm{g}$ with adsorbent dosage up to $4 \mathrm{~g}$. It appears that a plausible blocking of preferred adsorption sites for the MB occurs with increasing dosage of the BCBP adsorbent. This indicates that increasing adsorbent dosage facilitates some particle clustering and agglomeration which could block off preferred adsorption sites for the $\mathrm{MB}$ on the BCBP particles. Such particle agglomeration could also increase the heterogeneity of the adsorbent surface, thus, acting against the MB adsorption. Particle agglomeration is well known to decrease the available adsorption sites for an adsorbate from solution [22]. This must be the reason that the amount of MB adsorbed per unit mass of BCBP decreased with increasing BCBP dosage. 


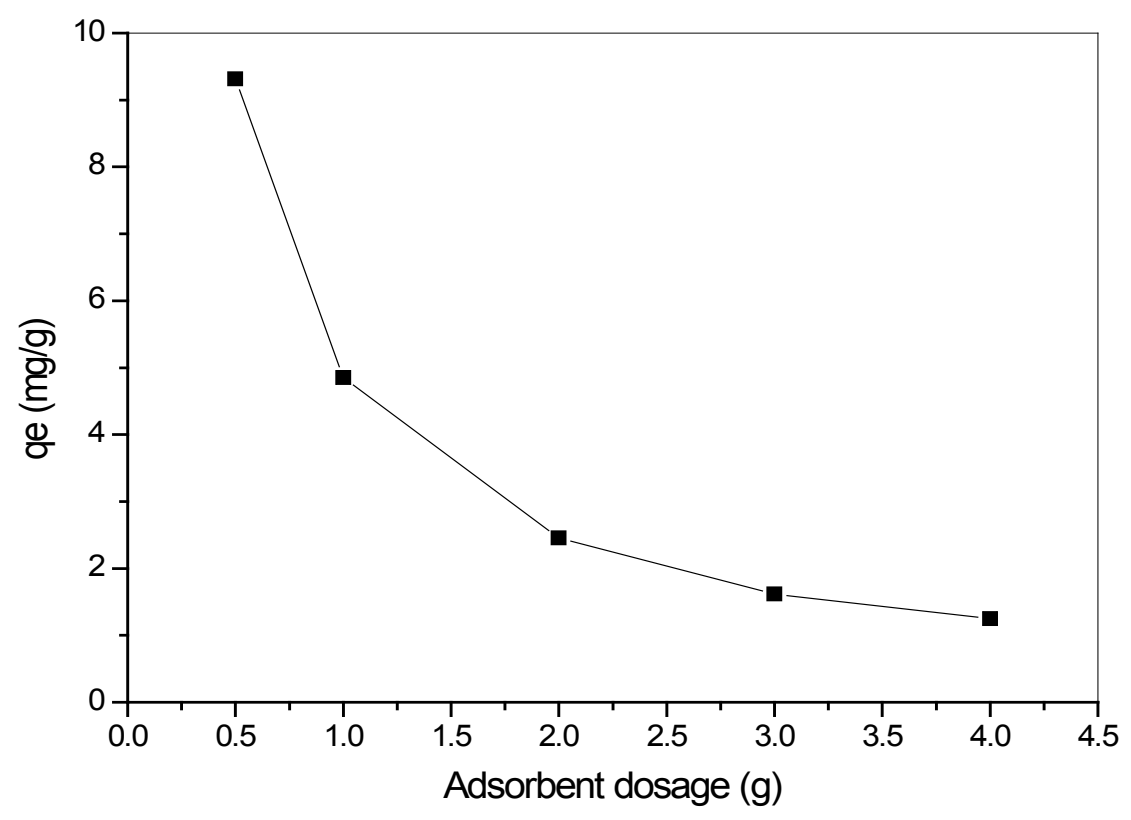

Figure 3. Effect of adsorbent dosage on the adsorption of MB.

\section{Effect of temperature on MB adsorption}

In the presence of $1 \mathrm{~g}$ of BCBP adsorbent and $100 \mathrm{~mL}$ of $50 \mathrm{mg} / \mathrm{L}$ of $\mathrm{MB}$ solution, the changes in the amount of $\mathrm{MB}$ dye adsorbed per unit mass of the $\mathrm{BCBP}$ adsorbent, $\mathrm{q}_{\mathrm{e}}$, for temperature varied between $30{ }^{\circ} \mathrm{C}$ to $70{ }^{\circ} \mathrm{C}$ is detailed in Fig. 4 . By increasing the temperature, the $\mathrm{q}_{\mathrm{e}}$ values continuously increased. From the result, the MB adsorption on BCBP adsorbent is weakly an endothermic process given that only approximately $2.4 \%$ increase occurred in the amount of MB dye adsorbed between $30{ }^{\circ} \mathrm{C}$ and $70{ }^{\circ} \mathrm{C}$. An increase in temperature should, expectedly, raise the kinetic energy (and hence mobility) of the MB molecules towards the BCBP surface. This should definitely increase dye-adsorbent interaction (and diffusion) rate and, hence, increase the amount of dye adsorbed at equilibrium. Nevertheless, the rather weak increase in $\mathrm{q}_{\mathrm{e}}$ within a $40{ }^{\circ} \mathrm{C}$ rise in temperature could either indicate that (i) higher temperature increases the MB solubility and encourages more residence in the solution than migration to, and adsorption on, the BCBP surface, or (ii) although the MB molecules arrive faster at the BCBP surface, increasing temperature could lead to subtle particle agglomeration which, in turn, limits the exposure of adsorption sites on the $\mathrm{BCBP}$ surface for the MB adsorption. 


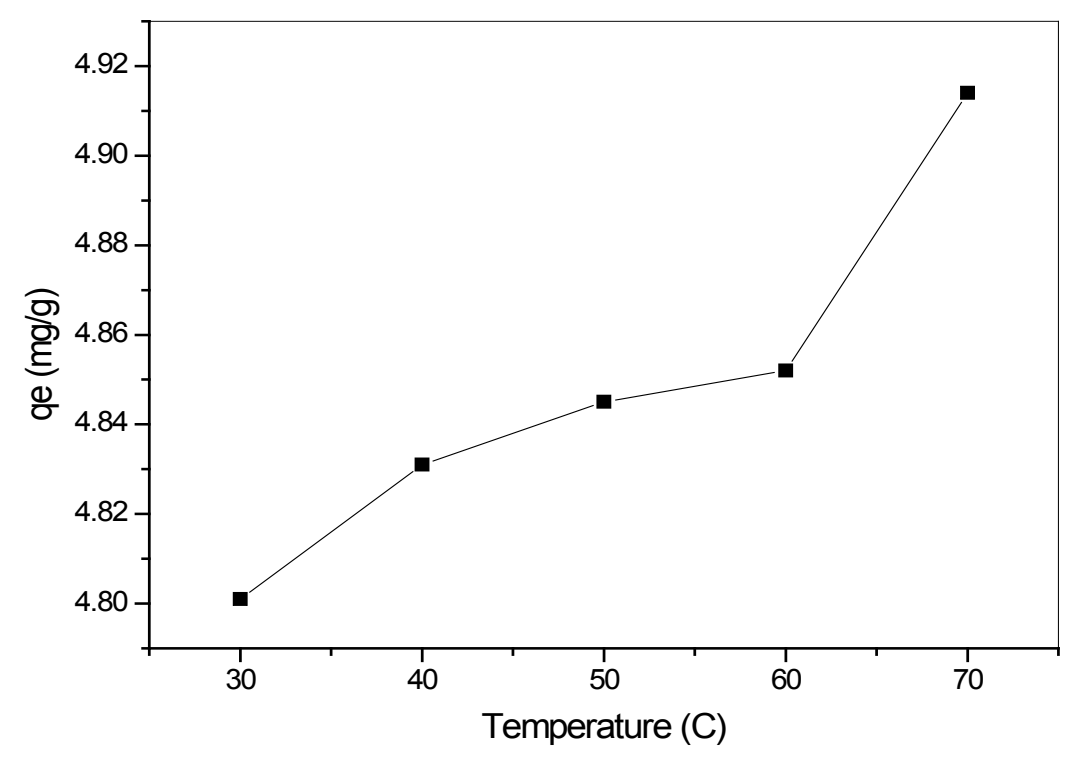

Figure 4. Effect of temperature on the adsorption of MB.

\section{Effect of pH on MB adsorption}

Fig. 5 shows the effect of $\mathrm{pH}$ on the amount of $\mathrm{MB}$ adsorbed per gram of the $\mathrm{BCBP}$ adsorbent, $\mathrm{q}_{\mathrm{e}}$, in the presence of $100 \mathrm{~mL}$ of $50 \mathrm{mg} / \mathrm{L} \mathrm{MB}$ solution, $1 \mathrm{~g}$ of BCBP adsorbent and during $80 \mathrm{~min}$ agitation time. The result shows that the amount of $\mathrm{MB}$ adsorbed per unit mass of the BCBP increases as $\mathrm{pH}$ increases from 2 to 8 and remained constant at $\mathrm{q}_{\mathrm{e}}=4.864 \mathrm{mg} / \mathrm{g}$ between $\mathrm{pH} 8$ and 10. At lower $\mathrm{pH}$, it seems that protonation of the dye molecule increased the repulsion between the $\mathrm{MB}$ and the positively charged sites on the BCBP surface. The tendency for MB molecules to become protonated at low $\mathrm{pH}$ [20] and to sustain its positive charge even up to $\mathrm{pH} 8$ [23] have been reported. It, therefore, appears that an increase in the density of negative charge on the adsorbent surface is responsible for increased attraction between the MB molecules and the BCBP surface as $\mathrm{pH}$ increases. Nevertheless, once the adsorption sites on the BCBP surface are fully occupied, $\mathrm{pH}$ effect on the MB adsorption may become negligible.

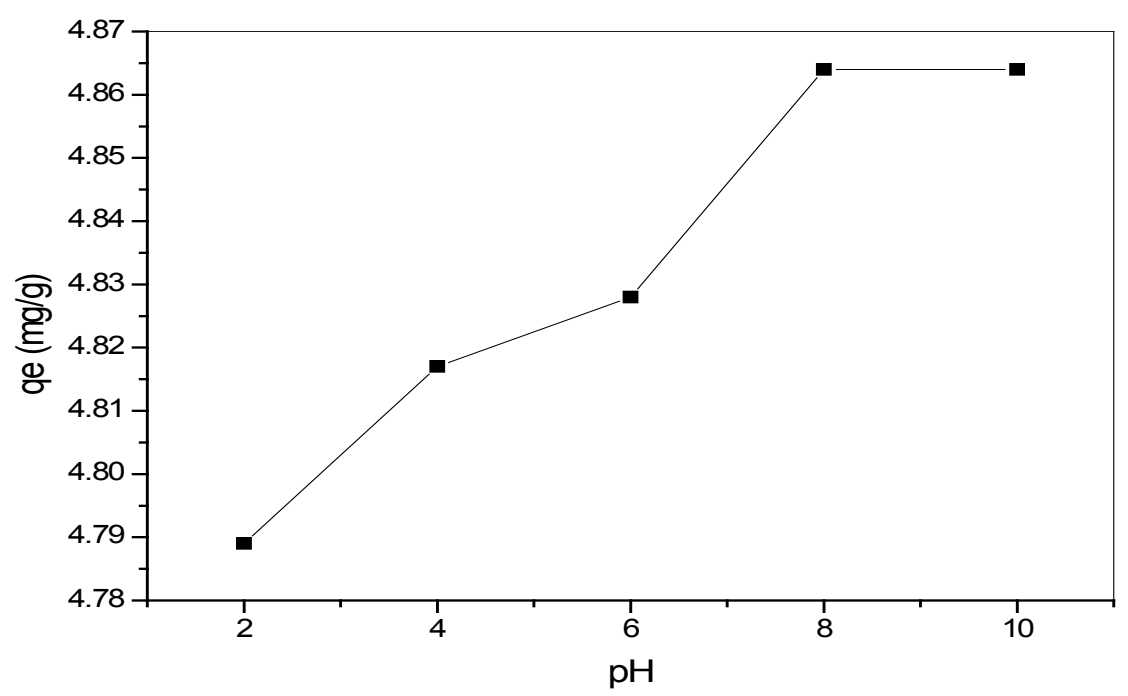

Figure 5. Effect of $\mathrm{pH}$ on the adsorption of MB. 


\section{Adsorption isotherm}

In order to fully understand the nature of the interaction between the MB dye and the BCBP adsorbent, the experimental data was analyzed according to the linear form of the Langmuir and Freundlich isotherms. The Langmuir isotherm can be represented by the following equation:

$$
\frac{C e}{q e}=\frac{i}{b}\left(\frac{1}{q m}\right)+\frac{C e}{q m},
$$

where $\mathrm{C}_{\mathrm{e}}$ is the equilibrium concentration $(\mathrm{mg} / \mathrm{L}), \mathrm{q}_{\mathrm{e}}$ is the amount of the dye adsorbed at equilibrium ( $\mathrm{mg} / \mathrm{g}$ ) and $\mathrm{q}_{\mathrm{m}}$ and $b$ are Langmuir constants which are related, respectively, to the adsorption efficiency and adsorption energy. For MB concentration $25 \mathrm{mg} / \mathrm{L}$ to $125 \mathrm{mg} / \mathrm{L}$ in the presence of $1 \mathrm{~g}$ of $\mathrm{BCBP}$ at $27{ }^{\circ} \mathrm{C}$, the values of $\mathrm{C}_{\mathrm{e}}$ and $\mathrm{q}_{\mathrm{e}}$ after $80 \mathrm{~min}$ agitation at $100 \mathrm{rpm}$ during, the plot of $\mathrm{C}_{\mathrm{e}} / \mathrm{q}_{\mathrm{e}}$ against $\mathrm{C}_{\mathrm{e}}$ for the Langmuir isotherm is provided in Fig. 6. The values of $\mathrm{q}_{\mathrm{m}}$ and $b$ were calculated from the slope and intercept of the plot, and their values (with correlation coefficient, $\mathrm{R}^{2}$ ) are presented in the Table 1. From the negative slope of the Langmuir isotherm plot as well as the very low $R^{2}$ value $(0.407)$, it can be concluded that the Langmuir isotherm cannot adequately describe the adsorption mechanism of the $\mathrm{MB}$ on the BCBP adsorbent. The Langmuir isotherm assumes that the adsorbate (MB) adsorbs on homogenous sites and forms a monolayer (without lateral growth) on the adsorbent (BCBP) surface with negligible intermolecular interaction between the adsorbate and the adsorbent.

The linear form of the Freundlich equation is as follows:

$$
\ln q e=\ln K+\left(\frac{1}{n}\right) \ln C e ;
$$

where $\mathrm{q}_{\mathrm{e}}$ is the amount of dye adsorbed at equilibrium, $\mathrm{C}_{\mathrm{e}}$ is the concentration of the dye solution at equilibrium (representing adsorption capacity) and $1 / \mathrm{n}$ is empirical constant (representing adsorption intensity). Apparently, the plot of $\ln q_{\mathrm{e}}$ versus $\ln \mathrm{C}_{\mathrm{e}}$ gave a straight line with a very high correlation coefficient $\left(\mathrm{R}^{2}=0.9579\right)$, as evidenced in Fig. 7. This confirms that the Freundlich isotherm, rather than the Langmuir isotherm, better describes the adsorption of MB dye on the BCBP adsorbent. The values of $\mathrm{K}$ and $1 / \mathrm{n}$, given in Table 1 , were extrapolated as the intercept and slope, respectively, of the plot. The adsorption of $\mathrm{MB}$ on the surface of Ricinun communis epicarp activated carbon also followed the Freundlich adsorption isotherm [20]. From the present result, the value of $1 / \mathrm{n}<1$ implies that the adsorption of the MB onto the BCBP adsorbent is highly favorable and physical in nature. Based on the Freundlich model, the MB dye is definitely held by weak van der Waals force of attraction and certainly adsorbed on heterogeneous sites on the BCBP surface.

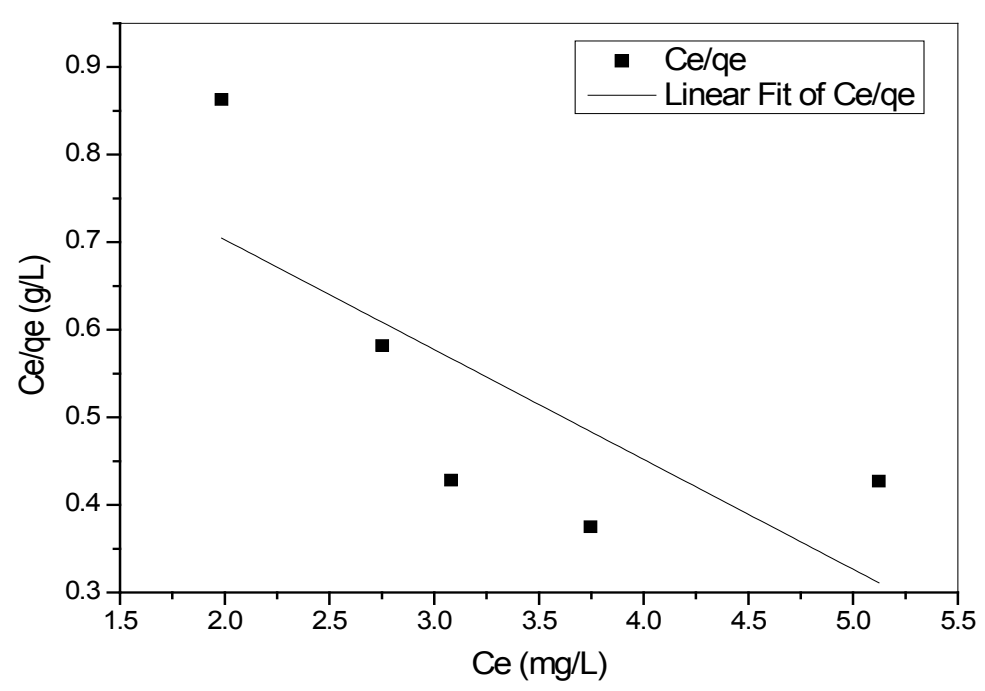

Figure 6. Langmuir isotherm plot for $\mathrm{MB}$ dye onto $\mathrm{BCB}$ powder. 


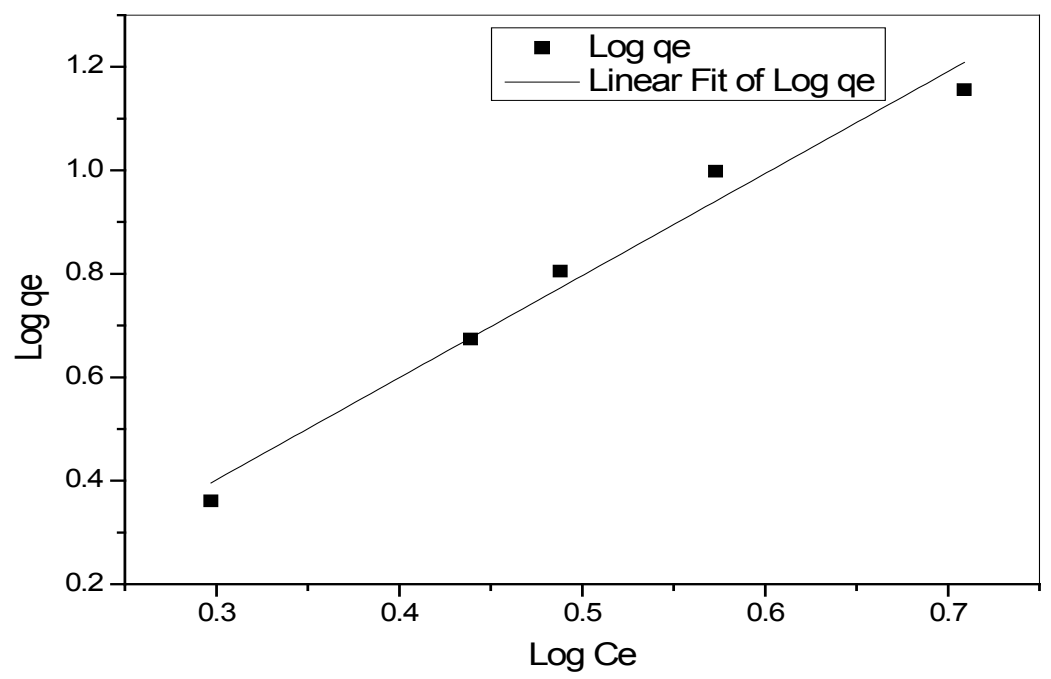

Figure 7. Freundlich isotherm plot for $\mathrm{MB}$ dye onto $\mathrm{BCB}$ powder.

Table 1. Langmuir and Freundlich isotherm parameters for the adsorption of MB onto BCBP.

\begin{tabular}{|l|c|c|c|c|c|}
\hline \multicolumn{3}{|c|}{ Langmuir } & \multicolumn{3}{c|}{ Freundlich } \\
\hline $\mathrm{Q}_{\mathrm{m}}(\mathrm{mg} / \mathrm{g})$ & $\mathrm{b}$ & $\mathrm{R}^{2}$ & $1 / \mathrm{n}$ & $\mathrm{K}(\mathrm{mg} / \mathrm{g})(\mathrm{L} / \mathrm{mg})^{1 / \mathrm{n}}$ & $\mathrm{R}^{2}$ \\
\hline 23.49 & 0.23 & 0.407 & 0.0968 & 0.280 & 0.9579 \\
\hline
\end{tabular}

\section{Adsorption Kinetics}

In the presence of $50 \mathrm{mg} / \mathrm{L}$ of $\mathrm{MB}, 1 \mathrm{~g} / \mathrm{L}$ BCBP adsorbent dosage and during contact time $20 \mathrm{~min}$ to $120 \mathrm{~min}$ at temperature of $27{ }^{\circ} \mathrm{C}$, the adsorption kinetics of MB onto BCBP adsorbent was tested for both pseudo-first and pseudo-second reaction orders. The plot of $\ln \left(\mathrm{q}_{\mathrm{e}}-\mathrm{q}_{\mathrm{t}}\right)$ against contact time, $\mathrm{t}$, is provided in Fig. 8, for the pseudo-first order reaction model, where $\mathrm{q}_{\mathrm{e}}$ is the equilibrium amount of $\mathrm{MB}$ adsorbed per unit mass of the BCBP adsorbent and $\mathrm{q}_{t}$ is the amount of $\mathrm{MB}$ adsorbed onto $\mathrm{BCBP}$ at any time, $\mathrm{t}$. The rate constant for the pseudo-first order reaction, $\mathrm{k}_{1}$, was calculated as the slope while the calculated $\mathrm{q}_{\mathrm{e}}$ value was extrapolated from the intercept of the plot. The values of the $\mathrm{k}_{1}$ and calculated $\mathrm{q}_{\mathrm{e}}$, as well as the correlation coefficient of the plot, are provided in Table 2. The results from Fig. 8 and Table 2 show high non-correlation between the experimental and calculated values of $\mathrm{q}_{\mathrm{e}}$, as well as very low correlation coefficient $\left(\mathrm{R}^{2}=0.538\right)$. This indicates that the adsorption of MB unto the BCBP does not follow a first order reaction kinetics. For the pseudo-second order reaction kinetics, the plot of $\left(\mathrm{t} / \mathrm{q}_{\mathrm{t}}\right)$ versus time, $\mathrm{t}$, is provided in Fig. 9. The values of the pseudo-second order reaction rate constant, $\mathrm{k}_{2}$, and the calculated value of qe were extrapolated, respectively, from the slope and intercept of the plot. Their values and the correlation coefficient of the plot are provided in Table 2. A strong agreement existed between the average experimental $\mathrm{q}_{\mathrm{e}}$ value $(4.742 \mathrm{mg} / \mathrm{g})$ and the calculated $\mathrm{q}_{\mathrm{e}}$ value $(4.740 \mathrm{mg} / \mathrm{g})$. Table 2 also reveals a very high correlation coefficient value $\left(\mathrm{R}^{2}=0.999\right)$. This shows that the kinetics of adsorption of the $\mathrm{MB}$ onto $\mathrm{BCBP}$ adsorbent can actually be explained using the second order reaction model. Similar second order reaction kinetics was also reported for the adsorption of MB onto steam-activated carbons developed from date pits [24]. 


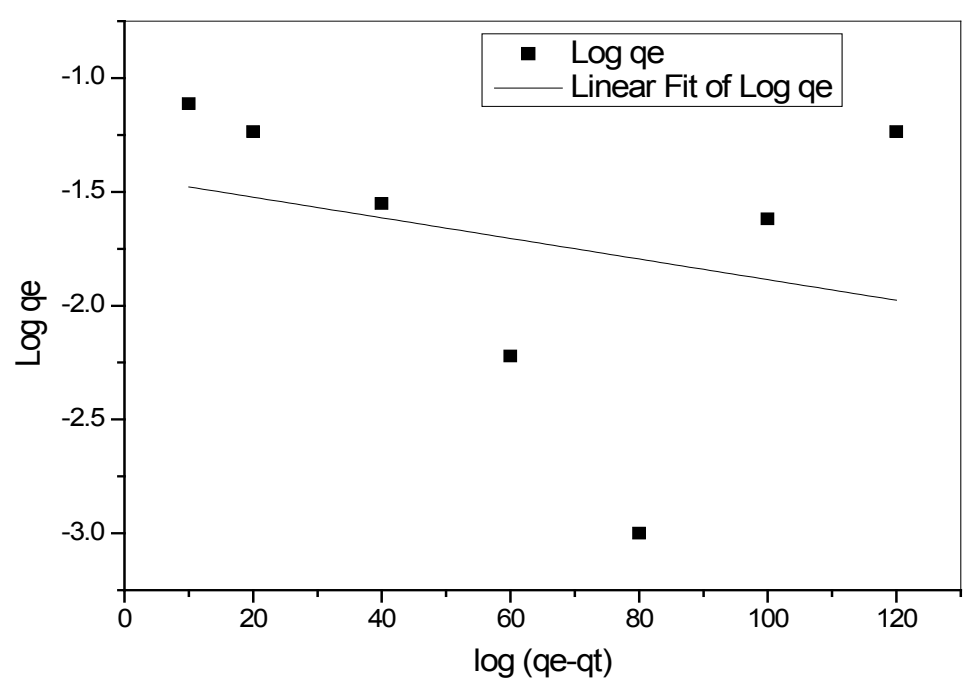

Figure 8. Pseudo first order plot for $\mathrm{MB}$ dye onto $\mathrm{BCB}$ powder.

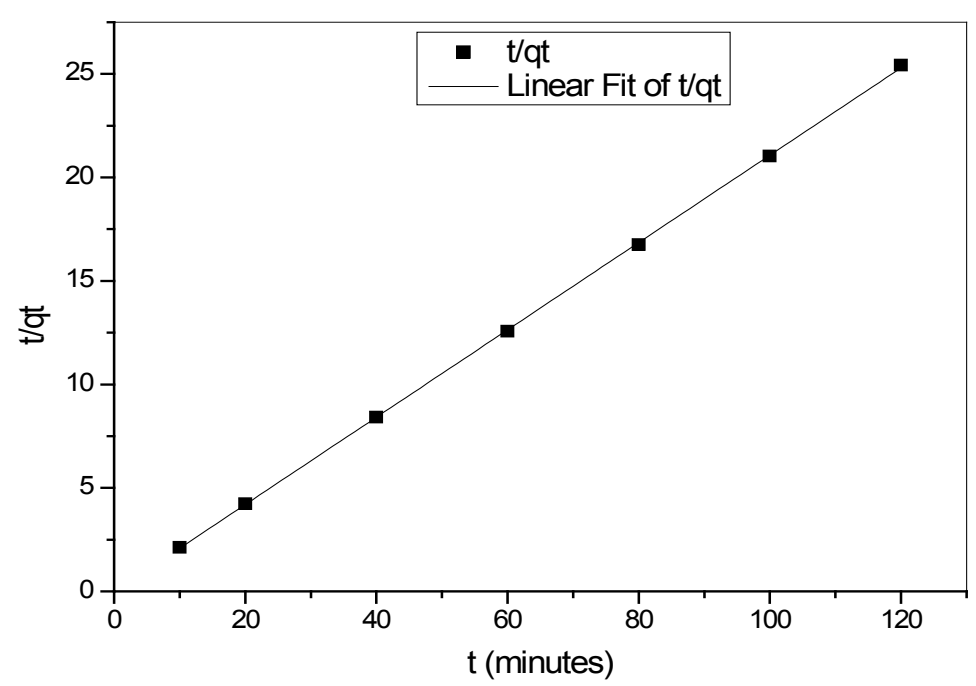

Figure 9. Pseudo second order plot for MB dye onto BCB powder.

Table 2. Pseudo-first and pseudo-second reaction order data for the adsorption of $\mathrm{MB}$ onto BCBP at $27^{\circ} \mathrm{C}$.

\begin{tabular}{llll|lll}
\hline \multicolumn{3}{c|}{ First order } & \multicolumn{3}{c}{ Second order } \\
\hline $\mathrm{q}_{\mathrm{m}(\text { exp. })}$ & $\mathrm{k}_{1}$ & $\mathrm{R}^{2}$ & $\begin{array}{l}\mathrm{q}_{\mathrm{m} \text { (cal. })} \\
(\mathrm{mg} / \mathrm{g})\end{array}$ & $\begin{array}{l}\mathrm{k}_{2} \\
(\mathrm{~g} / \mathrm{mg} / \mathrm{min})\end{array}$ & $\begin{array}{l}\mathrm{q}_{\mathrm{m} \text { (cal. })} \\
(\mathrm{mg} / \mathrm{g})\end{array}$ & $\mathrm{R}^{2}$ \\
\hline 4.79 & 0.015 & 0.037 & 0.110 & 0.189 & 4.74 & 0.999 \\
\hline
\end{tabular}

\section{Adsorbent characterization}

The FTIR spectra of BCBP before and after adsorption (Figs.10 and 11) of MB dye were analyzed to determine the vibration frequency changes in their functional groups. For BCBP before adsorption, various peaks are at $3421.72 \mathrm{~cm}^{-1}$ (O-H stretch, H-bonded), $2922.24 \mathrm{~cm}^{-1}$ (C-H stretch from alkane), $2361.69 \mathrm{~cm}^{-1}\left(\mathrm{C} \equiv \mathrm{N}\right.$ stretch), $1637.33 \mathrm{~cm}^{-1}(\mathrm{~N}-\mathrm{H}$ stretch$), 1508.47 \mathrm{~cm}^{-1}(\mathrm{~N}-\mathrm{O}$ asymmetric stretch), $1384.28 \mathrm{~cm}^{-1}$ (C-N stretch), $1035.57 \mathrm{~cm}^{-1}\left(\mathrm{C}-\mathrm{O}\right.$ stretch) and $668.93 \mathrm{~cm}^{-1}(\mathrm{C}-\mathrm{Br})$ 
[25].After adsorption of MB dye it was found out that most of the functional groups were affected after the uptake process. This is judged from shifts in the position of some of the functional groups to lower frequency or band intensity before and after MB adsorption such as $\mathrm{C}-\mathrm{O}, \mathrm{C}-\mathrm{N}, \mathrm{N}-\mathrm{O}, \mathrm{N}-\mathrm{H}$, $\mathrm{C}-\mathrm{H}$, and $\mathrm{O}-\mathrm{H}$ from $1035.57,1384.28,1508.47,1637.33,2922.24$ and $3421.72 \mathrm{~cm}^{-1}$ to 1034.40 , $1372.36,1507.77,1559.44,2919.24$ and $3417.28 \mathrm{~cm}^{-1}$ respectively. This indicates involvement of these groups for MB binding to BCBP [26].

Also, Fig. 12 shows the SEM images of BCBP powder. It can be observed from Fig. 12 that the external surface of BCBP powder is very irregular with rough edges but showing very few or no pores.

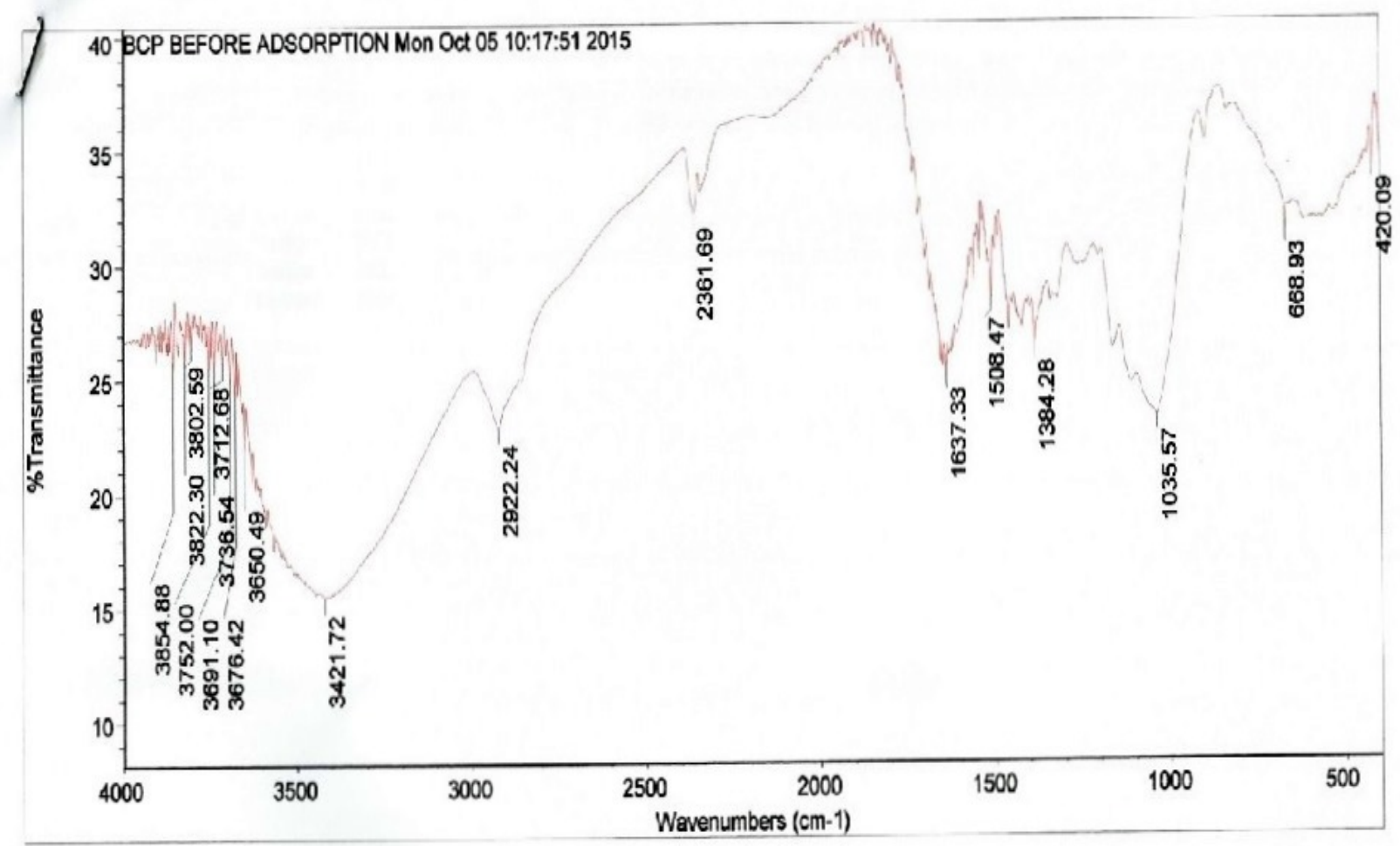

Figure 10. FTIR spectra of BCBP before adsorption.

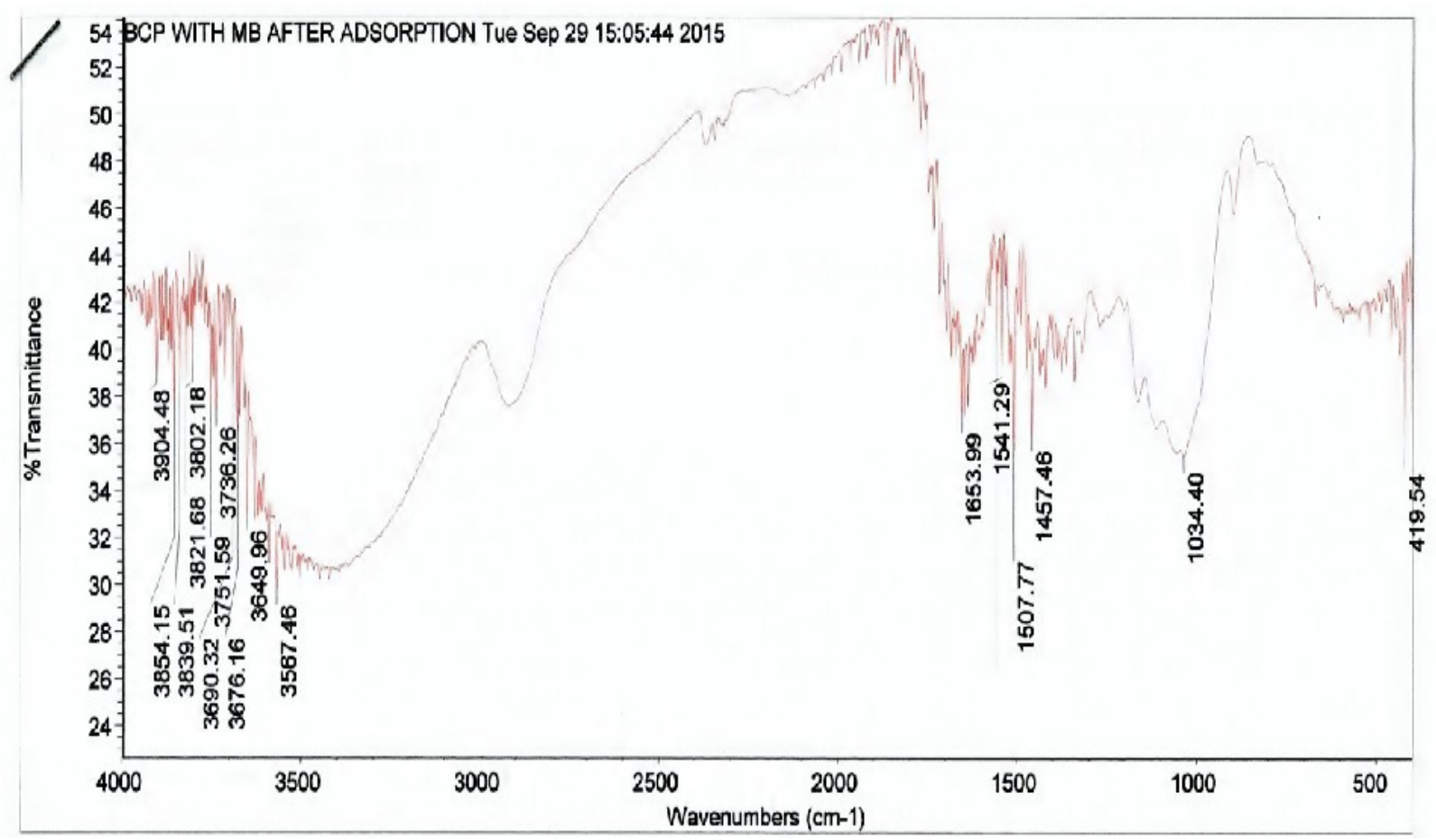

Figure 11. FTIR spectra of BCBP after adsorption. 


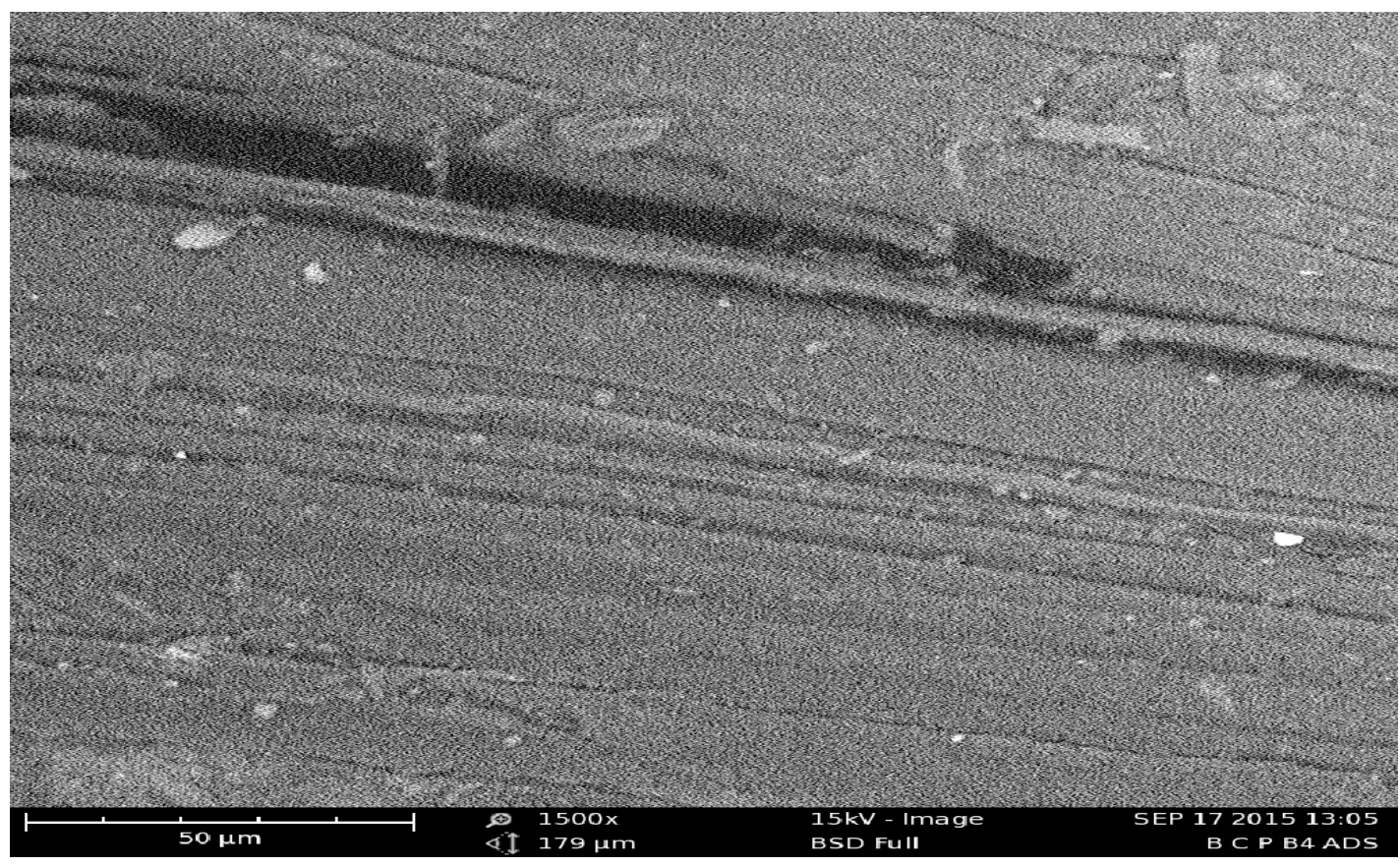

Figure 12. SEM micrographs of BCBP powder surface at magnification $1500 \times$.

\section{Comparison with Other Adsorbents}

Table 3 summarizes the comparison of the maximum MB adsorption capacities of few adsorbents including BCBP. This preliminary study concerning the adsorption capacities of BCBP indicate great potential for the removal of dye stuff from aqueous solutions. Although the adsorption capacities are, to some extent, lower than many of the reported adsorbents, the main advantages are the substantially lower cost of the material and easy accessibility. These preliminary results warrant further investigations such as activating the adsorbent (BCBP) using either acids or bases, further investigation of the isotherm studies at higher temperatures and using continuous flow processes to evaluate BCBP adsorption capacities.

Table 3. Comparison of maximum adsorption capacities for MB dye onto various adsorbents.

\begin{tabular}{|l|l|l|}
\hline Adsorbents & $\mathbf{q}_{\mathbf{e}} \mathbf{( m g / g )}$ & Reference \\
\hline Jack fruit peel & 285.71 & Hameed [14] \\
\hline Broad bean peel & 192.7 & Hameed and El-Khaiary [17] \\
\hline Pine apple stem & 119.05 & Hameed et al. [16] \\
\hline Garlic peel & 82.64 & Hameed and Ahmad [15] \\
\hline Cashew nut shell activated carbon & 68.72 & Kumar et al. [27] \\
\hline Citric acid treated rice hulls & 33.56 & El-Maghraby \& El-Deeb [28] \\
\hline RCP & 32.26 & Enenebeaku et al. [29] \\
\hline BCBP & 23.49 & This study \\
\hline Cereal chaff & 20.3 & Han et al. [30] \\
\hline Orange peel & 18.6 & Annodurai et al. [31] \\
\hline Gulmohar (Delonix regia) & 0.03 & Ponnusami et al. [19] \\
\hline
\end{tabular}




\section{Conclusion}

The adsorption of methylene blue dye onto bush cane bark powder has been studied. Increasing contact time will increase the amount of MB dye adsorbed up to an optimum value, beyond which the amount of dye adsorbed decreases. Increasing initial dye concentration, temperature and $\mathrm{pH}$ led to increasing amount of $\mathrm{MB}$ adsorbed onto the $\mathrm{BCBP}$ adsorbent. Based on isotherm and kinetics studies, the MB dye adsorb on the heterogeneous sites on the BCBP surface and followed a second order reaction mechanism.

\section{References}

[1] W.T. Tsai et al., Adsorption of acid dye onto activated carbons prepared from agricultural waste bagasse by $\mathrm{ZnCl}_{2}$ activation, Journal of Chemosphere. 45(1) (2001) 51-58.

[2] K. Santhy, P. Selvapathy, Removal of reactive dyes from wastewater by adsorption on coir pith activated carbon, Bioresource Technology. 97(11) (2006) 1329-1336.

[3] A. Reife, Dyes, environmental chemistry, in: Kirk-Othmer (Ed.), Encyclopedia of Chemical Technology, John Wiley \& Sons, Washington, 1993.

[4] U. Pagga, D. Brown, The degradation of dyestuffs: Part II. Behaviour of dyestuffs in aerobic biodegradation test, Chemosphere. 15(4) (1986) 479-491.

[5] M.F. Boeniger, Carcinogenity of azo dyes derived from benzidine, Department of Health and Human Services (NIOSH), Pub. No. 80-119 Cincinnati, OH, USA, 1980.

[6] O. Dursun, D. Gulbeyi, O. Ahmet, Methylene blue adsorption from aqueous solution by dehydrated peanut hull, Journal of Hazardous Materials. 144(1) (2007) 171-179.

[7] A.S. Franca, L.S. Oliveira, M.E. Ferreira, Kinetics and equilibrium studies of methylene blue adsorption by spent coffee ground, Desalination. 249(1) (2009) 267-272.

[8] Md. Tamez Uddin et al., Adsorptive removal of methylene blue by tea waste, Journal of Hazardous Materials. 164(1) (2009) 53-60.

[9] A. Mokhtar et al., Removal of dyes from colored textile wastewater by orange peel adsorbent: Equilibrium and kinetic studies, Journal of Colloids and Interfacial Science. 288(2) (2005) 371-376.

[10] A. Ola et al., Use of rice husk for adsorption of direct dyes from aqueous solution: A case study of direct F. Scarlet, Egyptian J. Aquatic Res. 31(1) (2005) 1-11.

[11] L.S. Tan, K. Jain, C.A. Rozaini, Adsorption of textile dye from aqueous solution on pretreated mangrove bark, an agricultural waste: Equilibrium and kinetic studies, J. App. Sci. Environ. Sani. 5(3) (2010) 266-276.

[12] S.N. Ijioma et al., Antinociceptive property of Costus afer ker stem juice and ethanol leaf extract in albino rats, Comprehensive Journal of Medical Sciences. 2(2) (2014) 14-19.

[13] A.N. Ezejiofor, C.N. Orish, E.O. Orish, Effect of aqueous leaves extract of Costus afer ker Gawl (Zingiberaceae) on the liver and kidney of male albino Wister rat, Ancient Science of Life. 33(1) (2013) 4-9.

[14] B.H. Hameed, Removal of cationic dye from aqueous solution using jackfruit peel as nonconventional low cost adsorbents, Journal of Hazardous Materials. 162(1) (2009) 344-350.

[15] B.H. Hameed, A.A. Ahmad, Batch adsorption of methylene blue from aqueous solution by garlic peel, an agricultural waste biomass, Journal of Hazardous Materials. 164(2) (2009) $870-875$. 
[16] B.H. Hameed, R.R. Krishni, S. A. Sata, A novel agricultural waste adsorbent for the removal of cationic dye from aqueous solutions, Journal of Hazardous Materials. 162(1) (2009) 305311.

[17] B.H. Hameed, M.I. El-Khaiary, Sorption kinetics and isotherm studies of a cationic dye using agricultural waste: broad bean peels, Journal of Hazardous Materials. 154(1) (2008) 639-648.

[18] B.H. Hameed, Evaluation of papaya seeds as a novel nonconventional low-cost adsorbent for removal of methylene blue, Journal of Hazardous Materials. 162(2) (2009) 939-944.

[19] V. Ponnusami, V. Gunasekar, S.N. Srivastava, Kinetics of methylene blue removal from aqueous solution using gulmohar delonix regia plant leaf powder: Multivariate regression analysis, Journal of Hazardous Materials. 169(1) (2009) 119-127.

[20] T. Santhi, S. Manonmani, Removal of Methylene blue from aqueous solution by bioadsorption onto Ricinus communis epicarp activated carbon, Chemical Engineering Research Bulletin. 13(1) (2009) 1-5.

[21] S.A. Dhahir et al., Adsorption of malachite green dye from aqueous solution onto Iraqi raw Al-Hussainiyat clay, Eur. Chem. Bull. 2(11) (2013) 866-872.

[22] M. Shanthi, V. Kuzhalosai, Photocatalytic degradation of an azo dye, Acid Red 27, in aqueous solution using nano $\mathrm{ZnO}$, Indian Journal of Chemistry. 51A (2011) 428-434.

[23] M.H. Elhussien, Y.M. Isa, Langmuir, Freundlich adsorption isotherms and kinetics for the removal of methylene blue dye from aqueous solution using activated carbon derived from pods of Acacia nilotica var astringens (Sunt tree) by chemical activation with $\mathrm{ZnCl}_{2}$, Chemical and Process Engineering Research. 38 (2015) 25-34.

[24] S.S. Ashour, Kinetic and equilibrium adsorption of methylene blue and remazol dyes onto steam-activated carbons developed from date pits, Journal of Saudi Chemical Society. 14(1) (2009) 47-53.

[25] M.L. Gary et al., Introduction to Spectroscopy: Infrared spectroscopy, $4^{\text {th }}$ ed., Bellingham, Brooks/Cole, Washington, 2010, pp. 15-87.

[26] N. Sharma, B.K. Nnadi, Utilization of sugarcane baggase, an agricultural waste to remove malachite green dye from aqueous solution, J. Mater. Environ. Sci. 4(6) (2013) 1052-1065.

[27] P.S. Kumar et al., Adsorption of methylene blue dye from aqueous solution by agricultural waste: Equilibrium, thermodynamics, kinetics, mechanism and process design, Colloid Journal. 3 (2011) 651-661.

[28] A. El-Maghraby, H.A. El-Deeb, Removal of a basic dye from aqueous solution by adsorption using rice hulls, Global NEST. J. 13(1) (2011) 90-98.

[29] C.K. Enenebeaku et al., Equilibrium and thermodynamic studies for adsorption of methylene blue dye onto raw cassava peel (RCP), Journal of Emerging Trends in Engineering and Applied Sciences. 7(3) (2016) 133-142.

[30] R. Han et al., Biosorption of methylene blue from aqueous solution by fallen phoenix tree leaves, Journal of Hazardous Materials. 141(1) (2007) 156-162.

[31] G. Annadurai, R.S. Juang, D.J. Lee, Use of cellulose based waste for adsorption of dyes from aqueous solutions, Journal of Hazardous Materials. 92(3) (2002) 263-274. 